\title{
Organizational Resilience: The Theoretical Model and Research Implication
}

\author{
Lei $\mathrm{XIAO}^{\mathrm{a}}$, Huan $\mathrm{CAO}^{\mathrm{b}}$ \\ Economic and Business School, University of Electronic Science and Technology of China, Chengdu, China \\ axiaolei@uestc.edu.cn, ${ }^{b}$ caohuan@uestc.edu.cn
}

\begin{abstract}
Organizations are all subject to a diverse and ever changing and uncertain environment. Under this situation organizations should develop a capability which can resist the emergency and recover from the disruption. Base on lot of literature, the paper provides the main concept of organizational resilience; construct the primary theoretical model and some implications for management.
\end{abstract}

\section{Introduction}

In recent years, the management of crises and disasters has become a key topic of concern for both practitioners and academics. Natural disasters, pandemic disease, terrorist attacks, economic recession, equipment failure and human error can all pose both a potentially unpredictable and severe threat to the continuity of an organization's operation. (Bhamra et al., 2011 ${ }^{[1]}$, Zolli \& Healy, 2012 $2^{[2]}$ ). The annual number of these high-risk events worldwide has steadily increased from around 350 in 1980 to almost 1000 in 2014 and the direct loss increased by $\$ 250$ billion from $\$ 50$ billion (UN, 2015). Different organizations have different reaction when facing these destructive dangerous situations, some organizations have been successfully adjusted and continue to grow and some organizations are lack of response and eventually closed down.

Crises may precipitate form a number of sources, but regardless of their severity or intensity, the challenges crises need for varying approaches to deal with them. In the attack of disruptive environment, why some organizations succeed while others failed? Coutu (2002) ${ }^{[3]}$, Hamel \& Välikangas (2003) [4] presented the "Organizational Resilience" in Harvard Business Review. In recent years, the literatures about organizational resilience have increased in academic journals.

What is the organizational resilience, which elements it consists, and how its management implications and such as a series of questions are mentioned on the research agenda. This article summarizes the existing organizational toughness literature, firstly we review the concept and factors of organizational resilience, then the paper propose a theoretical model of organizational, the last is the implication to management research.

\section{The concept of Organizational Resilience}

The term "resilience" comes from the Latin word "resilire" (which means to leap or jump back). In the academic community Resilience first produced in the field of ecology. Holling (1973) ${ }^{[5]}$ considered that Resilience determines the persistence of relationships within a system and is a measure of the ability of these systems to absorb changes of state variables, driving variables, and parameters, and still persist. After then, resilience has been developed in many areas such as ecology (Walker et al. 2002 $2^{[6]}$ ), engineering (Hollnagel et al., 2006 $6^{[7]}$ ), psychology (Powley, 2009 ${ }^{[8]}$ ), organization management (Weick, 1993 ${ }^{[9]}$; Gilbert, Eyring, \& Foster, 2012 $2^{[10]}$ ). At present, there has no an uniform definition of organizational resilience ( Linnenluecke, $2017^{[11]}$ ). Scholars give the conception from the system point social, psychological point and strategic management point of view. Sutcliffe and Vogus (2003) ${ }^{[12]}$ argue that resilience is an organizational level phenomenon as the power of organizational units to resume, rebound, bounce back, or positively adjust untoward events. Lengnick-Hall et al. $(2011)^{[13]}$ defined organizational resilience as a firm's ability to effectively absorb, develop situation-specific responses to, and ultimately engage in transformative activities to capitalize on disruptive surprises that potentially threaten organization survival. Annarelli and Nonino $(2016)^{[14]}$ think resilience is a capability to face disruptions and unexpected events in advance thanks to the strategic awareness and a linked operational management of internal and external shocks. The research on resilience has experienced high reliability organization, positive organizational behavior, business model, and supply chain stages.

The organizational resilience is different from adaptability, agility, flexibility, improvisation, recovery, redundancy and robustness. Resilience involves the reaction of the organization under destruction, which emphasizes the ability of recover and develops in a state of uncertainty, discontinuity, and emergency.

In this paper, we define organizational resilience as 
organization's ability to restore to the original state even develops a new skill in disruptive conditions. In particular, organizational resilience has the following characteristics

1) Resilience is a capability under discontinuous, emergent internal and external environment. The organizational resilience is a potential capacity which cannot be perceived in operation activities of organization. But when the environment becomes disruptive and emergent, organizational resilience can take advantage for organization.

2) Resilience emphasis on survival, adaptability, bounce back and development under disruptive situation. Organizational resilience is recovery ability after destruction rather than a resistance to unexpected event. Organization with high resilience can adjust timely and shape a new capacity confronted with a variety of dramatic changes.

3) Organizational resilience is a multi-level conception and related to the organizational resources, routines and process. Resilience across levels including individuals, groups and organizations and depends on the interactions among different levels. Meanwhile, resilience is a process which affected by resources and routine of organization.

\section{The Factors of Organizational Resilience}

Some literatures put forward the factors and specific measurements of organizational resilience in various angles, this paper only list few representative ones. In a system viewpoint, Tierney (2003) ${ }^{[15]}$ dimensionalizes the construct with four dimensions of robustness, redundancy, resourcefulness and rapidity. Deniz and Arzu (2015) ${ }^{[16]}$ developed three dimension structure of organizational resilience: robustness, agility and integrity. In strategic viewpoint, McManus (2008) ${ }^{[17]}$ think that a resilient organization should need situation awareness, management of keystone vulnerabilities and adaptive capacity. Akgün, A. E., \& Keskin, H. (2014) ${ }^{[18]}$ considered lots of elements including competence orientation, deep social capital, original/unscripted agility, practical habits, behavioral preparedness and broad resource networks. In psychology and organizational behavior, Weick (1993) ${ }^{[9]}$ provides that ability to improvise, virtual role systems, organizational wisdom and respectful individual and social interactions have great impact on organizational resilience.

Another representative article is Lengnick-Hall et al. (2011) ${ }^{[13]}$, which divided organizational resilience into cognitive dimensions, behavior dimensions, and context dimensions. In other words, a resilient organization needs to express resilience completely in these three aspects. Cognitive resilience is a conceptual orientation that enables an organization to notice, interpret, analyze, and formulate responses in ways that go beyond simply surviving an ordeal. Behavioral resilience is the engine that moves an organization forward. This property enables a firm to learn more about the situation and to fully use its own resources and capabilities through collaborative actions. Contextual resilience provides the setting for integrating and using cognitive resilience and behavioral resilience. Contextual resilience is composed of connections and resources.

E. Cunha et al. (2013) ${ }^{[19]}$ deconstructed organizational resilience from three levels: individual level, group level, and organizational level. The employee is the basic elements of organization system and the individual resilience is the main source of organizational resilience. Individual has resilience does not mean that groups or organizations he or she belongs to also have such characteristics, there need some process to realize it.

\section{The Theoretical Model of Organizational Resilience}

Organizational resilience is a newer tradition in organizational theory that incorporates insights form both coping and contingency theories. Although some literatures have analyzed the concept and measurement of organizational resilience, there is still a lack of integrative construct. The empirical research is also difficult due to the unpredictability of crisis disasters and the lack of samples. Some scholars thought that organizational resilience is contextual which means a resilience specific to a certain situation. It is important to realize that resilience arises from a complex interplay of many factors at different levels of analysis (Van Der Vegt et al., $\left.2015^{[20]}\right)$. 


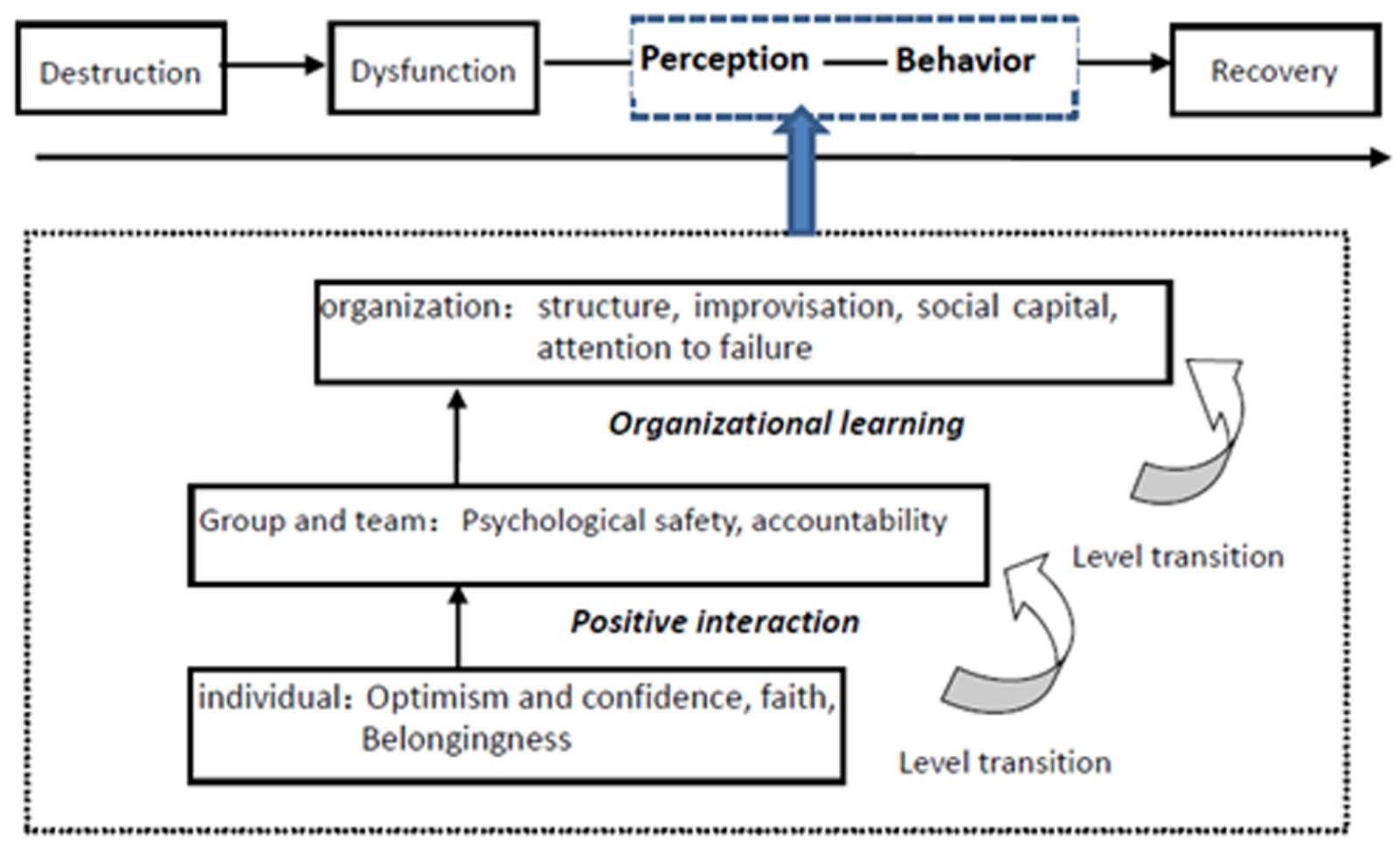

Figure 1. Theoretical model of organizational resilience

Combined with the work of Lengnick-Hall et al. $\left(2011^{[13]}\right)$ and Cunha et al. (2013) ${ }^{[19]}$, this paper regard that organizational resilience is influenced by many factors, many levels. We try to construct a multi- level and multi-factors model in Figure 1.

The paper think an organization need become resilient at individual level, group level and organization level. The factors of every level are different. Resilient individuals as part of the whole organizational system are expected to be a positive factor for organizations to develop their resilience capacity. The Personal character such as confidence, optimism, faith and belongingness are contributed to individual resilience (Luthans et al., 2006 ${ }^{[21]}$; Cunha et al., 2013 ${ }^{[19)}$ ). Resilient groups developed the capacity to see failures and imperfections as sources of learning and progress. Edmonson (2007) ${ }^{[22]}$ thought that a combination of psychological safety and accountability are critical ingredients for the group level. For the organizational level, the adaptive structures, improvisation, social capital and the attention to failure are the main factors.

In addition, there is a mutual influence between different levels. We think there is a "level transition" phenomenon from the low level to high level. The relation interaction between members can promote group resilience and organizational learning can help group to form organizational resilience.

The above model is only a preliminary idea, especially the impact of each dimension factors need to be determined, the overall follow-up also needs to be adjusted and improved in next work.

\section{The Quest for Management Research}

Resilience is generally seen as a desirable characteristic for an organization. More and more publications were found in academic journals, but there are lots of works to accomplish in management research.

1. The research of resilience need be strengthened. The academic community is already aware of the urgency of resilience and has some development in this area. However, there is a lack of research on the measurement, the realization mechanism and the relationship with other organizational variables, the advanced discussions of the organization's resilience developed slowly (Vegt et al. $2015)^{[20]}$. Linnenluecke (2017) ${ }^{[11]}$ pointed out that the context of resilience, organizing for resilience, measuring resilience and multi-level and cross disciplinary work are the primary research in future.

2. Combination of resilience and traditional problems. The other management research topics such as organizational culture, organizational structure, collective mind, social capital, psychological safety, supply chain and so on are relevant with organizational resilience. Once academia get consensus on the concept, measurement, model and mechanism of organizational resilience, lots of valuable problems can be studied.

3. Organizational resilience and the management practice. How to become a resilient organization? Especially under the crisis and disaster situations, utilize the organizational resilience theory to makes organizations overcome adversity. Resilience capacity can be developed and managed. For example, in the human resources management, managers can take specific HR principles and HR policies to enhance the employees and the overall organizational resilience.

\section{Conclusion}

Organizational resilience has been considered as an 
important field in management. This research give the concept, measures and integrated model of organizational resilience. The model includes lot of factors, relations and mechanisms. We find that there is great potential for future research within the area of resilience. For enterprises, they should be aware of the challenges of uncontinuous and disruptive environment and build resilience capability or prepare to do something in advance.

\section{Acknowledgement}

This paper was supported by Chinese Higher-education Institution General Research and Development Funding (ZYGX2015J161, ZYGX2014J101) and Ministry of Education in China, Humanities and social science projects (14YJC630001).

\section{References}

1. Bhamra, R., Dani, S., \& Burnard, K. (2011). Resilience: the concept, a literature review and future direction. International Journal of Production Research, 49(18), 5375-5393.

2. Zolli, A., \& Healy, A. M. (2012). Resilience: why things bounce back, Simon and Schuster.

3. Coutu, D. L. (2002). How resilience works. Harvard Business Review, 80(5), 46-56.

4. Hamel, G. and Välikangas, L. (2003). The quest for resilience. Harvard Business Review 81(9), 52-63.

5. Holling, C.S (1973). Resilience and stability of ecological systems. Annual Review of Ecology and Systematics, 4, 1-23.

6. Walker, J., \& Cooper, M. (2011). Genealogies of resilience from systems ecology to the political economy of crisis adaptation. Security dialogue, 42(2), 143-160.Ali E.

7. Hollnagel, E., Woods, D. D., \& Leveson, N. (2007). Resilience engineering: concepts and precepts. Ashgate Publishing, Ltd..

8. Powley, E. H. (2009). Reclaiming resilience and safety: resilience activation in the critical period of crisis. Human Relations, 62(9), 1289-1326.

9. Weick, K. E. (1993). The collapse of sensemaking in organizations: the Mann Gulch disaster. Administrative science quarterly, 38(4), 628-652.

10. Gilbert, M. Eyring, M. \& Foster, R.N. (2012). Two routes to resilience. Harvard Business Review,
90(12), 65-73

11. Linnenluecke, Martina K. (2017). Resilience in business and management research: a review of influential publications and a research agenda. International Journal of Management Reviews, 19(1), 4-30.

12. Sutcliffe, K. M., \& Vogus, T. J. (2003). Organizing for resilience. Positive organizational scholarship, 94-110.

13. Lengnick-Hall, C. A., Beck, T. E., \& Lengnick-Hall, M. L. (2011). Developing a capacity for organizational resilience through strategic human resource management. Human Resource Management Review, 21(3), 243-255.

14. JAlessandro Annarelli, \& Fabio Nonino (2016). Strategic and operational management of organizational resilience: current state of research and future directions. Omega, 62, 1-18.

15. Tierney, K. J. (2003). Conceptualizing and measuring organizational and community resilience: lessons from the emergency response following the September 11, 2001 attack on the World Trade Center, Univ. of Delaware, Newark, DE.

16. Deniz Kantur, Arzu İşeri -Say (2015). Measuring organizational resilience: a scale development. Journal of Business, Economics \& Finance, 4(3), 456-472.

17. McManus, S. (2008). Organisational resilience in New Zealand, Ph.D. thesis, University of Canterbury, Christchurch, New Zealand.

18. Akgün \& Halit Keskin (2014). Organizational resilience capacity and firm product innovativeness and performance. International Journal of Production Research, 52(23), 6918-6937.

19. E. Cunha, M. P., Castanheira, F., Neves, P., Story, J., Rego, A., \& Clegg, S. (2013). Resilience in organizations. Working paper

20. Van Der Vegt, G. S., Essens, P., Wahlström, M., \& George, G. (2015). Managing risk and resilience. Academy of Management Journal, 58(4), 971-980.

21. Luthans, F., Avey, J. B., Avolio, B. J., Norman, S. M., \& Combs, G. M. (2006). Psychological capital development: toward a micro-intervention. Journal of organizational behavior, 27(3), 387-393.

22. Edmondson, A. C. (2007). The competitive imperative of learning. Harvard business review, 86(7-8), 60-67. 